\title{
Del derecho y su violencia
}

\author{
Law and Violence
}

\author{
José María García Blanco \\ Universidad de Oviedo \\ jblanco@uniovi.es
}

Recibido: 10.11 .2010

Aprobado definitivamente: 03.06.2011

\section{RESUMEN}

La relación entre derecho y violencia se ha planteado tradicionalmente en el marco de la reflexión sobre la fundamentación del derecho. Tras pasar revista a los momentos teóricos más importantes en la historia de esta temática, el artículo se centra en los autores que han realizado tres de las más importantes aportaciones en el siglo XX a la misma: Benjamin, Derrida y Luhmann. Si bien los tres coinciden en el problema del carácter constitutivamente paradójico del derecho, difieren en su tratamiento. Benjamín y Derrida realizan una crítica y una deconstrucción, respectivamente, de lo que consideran violencia constitutiva del derecho, apoyándose para ello en una idea trascendente de justicia. En cambio, Luhmann desarrolla un análisis inmanente, sociológico, según el cual la semántica de la violencia más que dar indicaciones útiles para tratar el problema de fondo lo distorsiona. El articulo concluye con una reflexión que conecta el análisis de Luhmann con la teoría de la soberanía de Carl Schmitt: aunque antagónicas, norma y decisión son elementos fundamentales del derecho, pues sin decisiones no es posible instituir órdenes normativos, cuyo funcionamiento regular, además, presupone una normalidad fáctica que sólo es asegurada por el monopolio de las "decisiones últimas", más que por el de la violencia.

Palabras clave: Autorreferencia, crítica, decisión, deconstrucción, equidad/justicia, fuerza, incompletitud, paradoja, violencia.

\begin{abstract}
The relationship between law and violence has been analyzed traditionally within the framework of the reflection on law's foundation. The article reviews the most important theoretical moments in the history of the analysis of law's foundation and the role of violence, and then focuses on the authors who have made three of the most important contributions to this analysis in the twentieth century: Benjamin, Derrida and Luhmann. Although all three agree on the paradoxical foundation of law, they differ in their treatment. Benjamin and Derrida made a critique and a deconstruction, respectively, of what they consider the constitutive violence of law, guided by a transcendent idea of justice. Instead Luhmann develops and immanent (sociological) analysis, which leads him to argue that the semantics of violence does not provide useful indications for the analysis of the underlying problem, even distorts it. The article concludes with a reflection that connects the Luhmann's analysis with the Carl Schmitt's theory of sovereignty: although antagonists, norm and decision are the basic elements of law, because there is not possibility to establish
\end{abstract}


normative orders without decisions, and the monopoly of the "ultimate decisions", rather than that of violence, is what ensures the factual normalization required by the regular operation of any normative order.

KEYwords: Self-reference, Critique, Decision, Deconstruction, Equity / Justice, Force, Incompleteness, Paradox, Violence.

\section{SUMARIO}

1. De la epieíkeia y la cequitas al debate jurídico-sociológico sobre la legitimidad. 2. La hora de la crítica, revolucionaria y/o mesiánica. 3. De la crítica a la deconstrucción. 4. De la paradoja estructural del derecho y de cómo éste se deshace de ella. 5. A modo de conclusión. 
Sólo podemos decidir las cuestiones que son por principio imposibles de decidir

(Heinz von Foerster)

Draw a distinction!

(George Spencer-Brown)

\section{DE LA EPIEÍKEIA Y LA AEQUITAS AL DEBATE JURÍDICO-SOCIOLÓGICO SOBRE LA LEGITIMIDAD}

Ningún orden jurídico puede admitir que se le interpele si se ha instituido jurídicamente o no. En el marco operativo del sistema jurídico, la cuestión del derecho a decidir del derecho deja pronto de ser fructífera, por lo que, desde el punto de vista práctico, es preciso partir de la obligatoriedad del derecho, tomarla como un dato.

No obstante, casi desde los primeros pasos de la reflexión acerca del derecho hay muestras evidentes de una conciencia de su indeterminación lógica (cf. Platón, 2004: 483b ss.). Ahora bien, este tipo de cuestiones aparecen en el marco de la filosofía, primero, y, después, de la filosofía del derecho. Cuando por fin aparecen dentro de una teoría estricta del derecho, por la proximidad del análisis al propio sistema jurídico, como éste ha de olvidar la cuestión de su fundamentación, para ser operativo, la reflexión correspondiente debe ser cifrada; es decir, debe ocultar lo que realmente significa.

La forma más característica de presentación del problema ha sido la difusa idea de la existencia de un segundo derecho tras el derecho. Es así como en la Antigüedad se utiliza el concepto de cequitas lepieíkeia, estrechamente conectado con la cuestión del derecho inicuo. En la Edad Media, en buena medida como consecuencia de una creciente judicialización de las relaciones sociales, el problema pasa a ser tratado desde la perspectiva de la ruptura del derecho (derogatio/abrogatio), y en relación con cuestiones como el robo por necesidad y, con más alcance, el derecho de resistencia o los derechos particulares del monarca, que abre la puerta al famoso debate posterior sobre la razón de Estado.

En los siglos XVI y XVII, la cuestión del derecho del derecho es tratada en unos términos que combinan esta tradición con la innovación conceptual que aporta la sensibilidad hacia las teodiceas, tan característica de la transición hacia la moder- nidad. Es en esta época cuando podemos encontrar la famosa sentencia de Montaigne (2002: 1. III, c. XIII) acerca de la inutilidad de la reflexión filosófica para cambiar el rumbo del mundo, en especial el de la política y las leyes, de las que dice que "no hay nada que sea tan pesada y ampliamente pecador", por lo que "cualquiera que las obedezca por ser justas no las obedece justamente por lo que debe". Y esto es así porque "las leyes se mantienen vigentes no porque sean justas, sino porque son leyes", siendo en ello, y en nada más, que tiene su fundamento la autoridad; un fundamento que Montaigne califica de "místico"; lo que luego, cuatro siglos más tarde, servirá de inspiración a las reflexiones de Derrida sobre el fundamento del derecho, a las que me referiré posteriormente.

En el siglo XVII, siguiendo esta línea, Pascal unirá de forma más explícita a derecho y equidad/ justicia el tercer elemento clásico de la reflexión sobre el derecho del derecho, que ya estaba presente en el citado Gorgias de Platón: la fuerza. En los Pensamientos (1981: 103, La.), dice Pascal: "Es justo que se siga lo que es justo; es necesario que se siga lo que es más fuerte. La justicia sin la fuerza es impotente; la fuerza sin la justicia es tiránica". En consecuencia, "es preciso unir la justicia y la fuerza, y para ello hacer que lo que es justo sea fuerte o lo que es fuerte sea justo." Mas "la justicia está sujeta a discusión. La fuerza es perfectamente reconocible y sin discusión. Así, no se ha podido dar la fuerza a la justicia, porque la fuerza ha contradicho a la justicia y ha dicho que era injusta, y que ella era la justa." Por lo tanto, "no pudiendo hacer que lo que es justo sea fuerte, se ha hecho que lo que es fuerte sea justo".

Con este perfil, el problema del derecho del derecho alcanzará su tratamiento más clásico y elegante en Kant, cuando éste pone el origen del derecho en la fuerza y lo separa cuidadosamente de la justicia/ equidad. En el "Apéndice a la introducción a la teoría del derecho" de los Principios metafísicos de la doctrina del derecho (una de las partes de la Metafísica de las costumbres), Kant aborda el problema del "derecho equívoco", señalando, en modo de claras resonancias pascalianas, que "la equidad admite un derecho que no puede obligar, y la necesidad una exigencia sin derecho" (Kant, 1956: 341). Pero una y otra (equidad y necesidad) son presentadas por Kant como si fueran gemelas, en cuanto modos de 
lo que él llama un "derecho en sentido lato". Para el modo equitativo de este derecho lato, el derecho estricto es una injusticia muy grande; para el derecho de necesidad, ésta carece de ley. Pero el mal denunciado por la equidad no puede corregirse mediante el derecho, porque la reclamación equitativa sólo tiene fuerza ante el tribunal de la conciencia, no ante los tribunales civiles. A su vez, no puede haber necesidad que legalice la injusticia. La explicación del problema, y con ella la forma en que Kant formula su propuesta de solución de la cuestión del derecho del derecho, es curiosa: el problema es resultado de una confusión de los motivos objetivos y subjetivos del ejercicio del derecho (Kant, 1956: 343 s.), como consecuencia de la cual se supone la existencia de "casos de derecho dudosos, cuya decisión no puede encomendarse a ningún juez” (Kant, 1956: 341).

La forma de plantear el problema y salir de él por parte de Kant sólo puede comprenderse si se atiende a lo que él entiende por derecho objetivo, puro o estricto: el que va inseparablemente unido a la facultad de obligar (Kant, 1956: 338 s.). Sólo el derecho "puramente exterior" puede llamarse derecho puro. Y si bien se funda en la conciencia de la obligación general según la ley, para determinar la voluntad en consonancia con esta obligación el derecho no puede referirse a los móviles subjetivos, sino que ha de apoyarse por principio en la posibilidad de una fuerza exterior.

Esta acentuación de la fuerza como base de la validez del derecho, muy característica del siglo XVIII, está relacionada, en lo histórico, con un desplazamiento de la semántica jurídica de la potestas a la potentia, y desde ésta a la vis, probablemente como consecuencia de la experiencia del absolutismo. Pero no debe ignorarse la paralela renuncia a lo que podríamos llamar un continuo de racionalidad, en la línea defendida por el neoestoicismo. La razón parece que ya no puede ser a la vez base del conocimiento y de la validez, aunque ello no es obstáculo para que esa "fuerza exterior" sea "conciliable con la libertad de todos según leyes generales", y por tanto "racional" (Kant, 1956: 339 s.).

La fuerza viene a proporcionar, pues, una nueva posibilidad de encajar la no juridicidad del derecho dentro del derecho. En lo relativo al origen de éste, permite la emancipación de la teología y de las especulaciones acerca de un estado de naturaleza, así como prescindir de las ficciones contractualistas.
Las cosas son mucho más sencillas: el origen del derecho es un principio extrajurídico, la fuerza. Con ello se pone de manifiesto, a la vez, que es la sociedad quien justifica el derecho, y no al revés; que la verdadera garantía del orden reside en la propiedad; y que el derecho, en definitiva, no precisa de justificación adicional como instrumento de tal orden. No obstante, también puede suponerse, como hace Kant, que todo poder, incluso cuando en origen está desprovisto de cualquier derecho, es conducido por una teleología hacia la constitución del derecho, y que de tal modo, con el curso de la historia, se ve abocado - por sí mismo- a la forma jurídica (cf. Folkers, 1979).

A esta asociación de derecho y coacción (externa) se referirá después críticamente Hegel, para quien fuerza y violencia, tomadas abstractamente, son injustas, porque se destruyen en su concepto inmediatamente a sí mismas, dado que la violencia sólo puede ejercer coacción como acción sobre la voluntad, pero justo esto es lo que no puede admitir (Hegel , 1986: § 91 y 92). Sin embargo, a renglón seguido (Hegel, 1986: § 93), señala que una violencia secundaria ejercida sobre la primaria es necesariamente justa y presupuesto de la legalidad.

Durante el XIX, el intento de poner en la fuerza el obstáculo decisivo al regreso al infinito que genera la reflexión sobre el derecho del derecho contará con escaso aprecio. Coacción y libertad no podían ser concebidas como coexistentes, y si se partía del derecho para coaccionar se planteaba la cuestión de por qué alguien debía estar obligado a reconocer este derecho como derecho. Pero esta ruta no condujo muy lejos: había que dar por supuesta la obligatoriedad del derecho, y, a lo sumo, adentrarse en las más plácidas, aunque salobres, aguas del debate jurídico-sociológico sobre la legitimidad, que tiene su punto culminante en las bien conocidas reflexiones de Jellinek y Weber.

En el siglo XX, la novedad más importante en el ámbito de nuestro problema de referencia es que, en cierto modo, adopta una forma que viene a invertir el resultado de la crítica hegeliana a Kant: la de una crítica de la violencia establecida ejercida en nombre de otra de inspiración revolucionaria. El problema alcanza, así, una radicalidad que puede dar la impresión de llevarlo por derroteros jurídica y sociológicamente poco o nada fructíferos, pero que, si se observa con detenimiento, muestra una notable 
pertinencia - cuando menos sociológica-, al presentarnos la violencia como una decisión tomada a consecuencia del carácter consustancialmente ambiguo del sistema del derecho.

\section{LA HORA DE LA CRÍTICA, REVOLUCIONARIA Y/O MESIÁNICA}

Las dos contribuciones quizá más originales realizadas, directa o indirectamente, durante la primera mitad del siglo XX al tema de la violencia y el derecho se elaboraron en sus primeras décadas: una es la de Sorel, en sus Réflexions sur la violence de 1906; la otra, la de Zur Kritik der Gewalt de Benjamin de 1921. Común a ambas es su planteamiento del problema en función de diferencias.

En el caso de Sorel (2005: 230 s.) se trata de diferenciar entre el conjunto de actos que tienen como objeto imponer la organización de un orden social en el cual gobierna una minoría y aquellos otros que tienden a la destrucción de ese orden. Sorel entendía que el concepto de violence debía ser reservado para el segundo tipo de actos, mediante los cuales el proletariado reacciona contra la force empleada sistemáticamente por la burguesía y el Estado para defender el orden capitalista.

Aunque influida en buena medida por las reflexiones de Sorel y su distinción fundamental, más interés tiene para nuestro objeto el ensayo de Benjamin, ya que pone al derecho en el primer plano de su análisis, y además lo hace poniendo un ojo en la filosofía del derecho de Kant y otro en la teología política de Carl Schmitt.

En el arranque del párrafo que cierra el mencionado ensayo, Benjamin señala que la crítica que acaba de realizar de la violencia es la filosofía de su historia, porque entiende que sólo la idea de su origen permite, en este caso, alcanzar el objetivo de toda crítica: desarrollar una perspectiva capaz de distinguir y decidir (Benjamin, 1993: 63).

Distinguir y decidir son operaciones que requieren criterios, y que en el caso de la crítica de la violencia nos remiten a su propio objeto, puesto que aquello que, según Benjamin, caracteriza a la violencia es su poder distintivo y decisorio. En otras palabras, la crítica benjaminiana de la violencia nos presenta a la violencia misma, pura, como crítica (como capacidad de distinguir y decidir).
La crítica, así entendida, se transforma en la idea metafísica, ontológica, de una "filosofía" de la historia de la violencia, de la idea de su origen, con lo que Benjamin se aparta en buena medida de la concepción tradicional de la crítica como juicio ilustrado y/o como investigación realizada desde un punto de vista trascendental.

El esquema empleado por Benjamin consiste en una disección de las relaciones, conexiones y correspondencias todavía existentes entre las definiciones teóricas tradicionales de las distintas formas de violencia, y que privan al distinguir de su capacidad corrosiva. Benjamin (1993: 29) comienza preguntándose si la violencia en general, como principio, puede ser moral cuando se emplea como medio para fines justos. Para responder a esta pregunta, distingue la violencia del derecho natural de la del derecho positivo. Mientras que para el primero la violencia es un producto natural, el segundo se eleva por encima de cualquier determinación natural de la misma, lo que le concede una mayor potencia distintiva. No obstante, iusnaturalismo y positivismo jurídico comparten un dogma fundamental, en virtud del cual quedan vinculados entre sí: que fines justos pueden ser alcanzados por medios legítimos, que medios legítimos pueden ser aplicados a fines justos (Benjamin, 1993: 31); en definitiva, el esquema instrumental medios-fines. En el fondo, pues, la contraposición entre derecho natural y positivo no es auténtica, ya que se incluyen mutuamente, en virtud de la circularidad que fundamenta tanto a uno como a otro. La meta principal de la crítica benjaminiana será, en consecuencia, romper ese círculo fundamentador de todo derecho, para así demostrar que entre fines justos y medios legítimos, y más en general entre la violencia como medio y fines justos, existe una contradicción insuperable. El mundo de los fines y el de los medios son incompatibles.

A pesar de esta incompatibilidad de principio, que hace perder pie tanto al derecho natural como al positivo, Benjamin entiende que este último y sus distinciones características permiten una observación crítica más fructífera, capaz de acercarnos a la verdadera naturaleza de la violencia y a su dimensión histórica. El soporte del positivismo jurídico, a este respecto, es la distinción entre violencia sancionada y no sancionada. La cuestión crítica, entonces, es la relativa al sentido de esta distinción, y para responder a ella Benjamin adopta un punto de vista 
externo a la filosofía jurídica positiva, como es el análisis de la conexión entre derecho y violencia en términos de una filosofía de la historia.

La distinción fundamental del derecho positivo en relación con la violencia, sin embargo, presupone otra distinción entre fines naturales, que se sustraen a todo reconocimiento histórico, y fines jurídicos, que justo se definen por ser fines históricamente reconocidos, sancionados (Benjamin, 1993: 32 s.). El objetivo de la distinción entre violencia sancionada y no sancionada es sustituir todos los fines naturales por fines jurídicos, para que, así, la violencia pueda ser monopolizada en nombre del derecho. Conforme a esta distinción, central para el derecho positivo, no puede haber violencia legítima alguna fuera del derecho, con la que la violencia queda disociada de todo fin natural, porque él mismo, como derecho, está fundado sobre la violencia y, en consecuencia, debe monopolizarla. De ahí que cualquier violencia extrajurídica represente una amenaza para él (Benjamin, 1993: 34 s.).

De esta manera, el sentido de la distinción sobre la que descansa el derecho positivo se convierte en el foco de atención de Benjamin, y el análisis que realiza de una de las escasas formas en que la violencia extrajurídica es aún admitida por el orden jurídico, como es el derecho de huelga, pone en claro que la violencia funda derecho. La violencia puede derrumbar un orden jurídico, transformarlo y erigir otro nuevo. Precisamente la preferencia concedida al derecho positivo - sobre el natural - y a su distinción entre fuerza sancionada y no sancionada es porque tal distinción viene a reconocer, de manera implícita, que la violencia produce derecho. Y este rasgo característico de la violencia es el "único fundamento seguro de su crítica" (Benjamin, 1993: 38). La violencia es en esencia productora de derecho, y no "violencia depredadora". No se trata de que, ocasional o accidentalmente, la violencia engendre derecho, sino que éste es su producto necesario. Si la violencia es el origen del derecho, entonces el objetivo de asegurarla como un principio está mucho más cercano.

Como fundadora de derecho, la violencia hace vislumbrar lo que al final de su ensayo Benjamin presenta como lo característico de la violencia en tanto violencia: ser algo cuya naturaleza no consiste en ser mero medio para un fin, sino en operar de forma inmediata. En cambio, en el marco de las relaciones sociales jurídicamente sancionadas, la violencia asume la forma de conservadora de derecho, al ponerse al servicio de fines jurídicos, y se convierte en un medio. De esta forma, la violencia queda adherida a lo que no es, y su "criterio" se exterioriza.

A pesar de que Benjamin insiste en la necesidad de mantener cuidadosamente esta distinción, inmediatamente señala que de la en sí inmediata fuerza fundadora resultan relaciones más o menos duraderas, que tienen un indudable carácter conservador, lo que le lleva a establecer una comunidad fundamental entre ambas violencias: la del destino. Si la violencia conservadora es "amenazadora al modo del destino", la fundadora es la "coronada por el destino" (Benjamin, 1993: 42). Esta es la razón de fondo de que, con la policía, ambas manifestaciones de la violencia fatal queden tan estrechamente conectadas entre sí que resulte extremadamente dificultoso tan sólo entrever la inmediatez de la violencia.

Así pues, ni siquiera la violencia fundadora es realmente inmediata, pues está corrompida por las relaciones que mantiene con el derecho que instituye. Al ser medio, también la violencia fundadora es impura. En cuanto entra en conexión con fines se hace ambigua, una marca indeleble del orden del destino. Es el resultado de mezclar lo que debe mantenerse separado, de la corrupción de lo puro por la vinculación con aquello que lo no es. La ambigüedad, por tanto, debe ser quebrada, y esto significa derribar el círculo del dogma fundamental, según el cual fines justos pueden ser alcanzados por medios sancionados y medios sancionados pueden ser aplicados a fines justos. Como medio, la violencia, sea instituyente o conservadora, no puede estar relacionada con fines justos.

Como deja claro el análisis que realiza Benjamin de las formas no coactivas de resolución de conflictos, la pureza del medio no es el problema. Medios puros - no violentos-, como dentro de ciertos límites es la huelga general, gracias a una "ruptura de relaciones", pueden conseguir una limitada superación del orden del destino y del derecho. Y si la violencia puede ser a este fin de ayuda, entonces es preciso buscar un tipo de violencia distinto a todos los contemplados por la teoría jurídica; esto es, una que no mantenga relación mediata alguna con lo que deba conseguirse, de forma que así se rompa el hilo conductor que une a la violencia fundadora de derecho con la contextura jurídica. Debe tratarse, 
pues, de una violencia que sea un fin en sí, que tenga su criterio en ella misma, no fuera de ella, y así no resultar corrompida. Para conseguir tal pureza debe romper cualquier posible relación con fines, pues sólo de esta forma puede ser inmediata, no susceptible de mediatización.

Para abordar esta nueva tarea, Benjamin introduce otra distinción: la que delimita esta violencia pura, por él postulada, de la violencia mítica. En realidad, entre ambas hay una notable analogía, ya que la violencia mítica, en su forma más arquetípica, es "pura manifestación de los dioses" (Benjamin, 1993: 55). El factor crítico para romper esta analogía es que la violencia mítica es incapaz de resolver lo que Benjamin identifica como el problema clave del derecho: la imposibilidad última de decidir todos sus problemas (Benjamin, 1993: 54). Ella, como violencia fatal - vinculada al destino- que es, puede decidir sólo sobre la legitimidad de los medios, no sobre la justicia de los fines, pues acerca de ésta sólo decide Dios (Benjamin, 1993: 54). Vedado como tiene el acceso a la justicia, "principio de toda determinación divina de fines" (Benjamin, 1993: 57), sólo le cabe producir poder, que es el "principio de toda institución mítica de derecho" (ibid.). En consecuencia, si bien es cierto que la violencia mítica no es en primera instancia violencia mediata, al ser generadora de poder es quien pone el "hito delimitador de la frontera entre lo humano y lo divino" (Benjamin, 1993: 56).

Violencia mítica y jurídica presentan, por tanto, la misma indeterminación: la que es característica del destino. La sistemática ambigüedad de ambas violencias es consecuencia de su función delimitadora, ya que donde se trazan límites el adversario no es aniquilado sin más, sino que se le reconocen derechos, aun cuando el vencedor goce de total superioridad (Benjamin, 1993: 57). Violencia instituyente y mítica no pueden ser, por ello, realmente destructivas: los límites que trazan no son radicales, no separan de verdad. La diferenciación producida por estas violencias se caracteriza por una ambigüedad insuperable, porque, si bien ninguna es mediata en sí, ambas son mediatizadas por el hecho de tener como fin la fundación de derecho. Una y otra, en consecuencia, son impuras. Romper con su impureza, con la mediatización que las hace ambiguas, es plantear la cuestión relativa a una violencia puramente inmediata, capaz de acabar con cualquier contenido mítico y su consustancial ambigüedad.

A esta violencia inmediata la denomina Benjamin "divina" porque el principio de su determinación de fines es, como hemos visto, la justicia. Libre de toda mediatización, se contrapone a la mítica, pues si ésta "instaura derecho, la divina lo destruye; si aquélla traza límites, ésta los elimina; si la mítica culpabiliza y expía a la vez, la divina exculpa; si aquélla amenaza, ésta fulmina; si una es sangrienta, la otra es letal pero de forma incruenta" (Benjamin, 1993: 59). Gracias a ello, la violencia divina rompe los vínculos constitutivos del fatal ámbito del mito y las ambiguas diferencias establecidas por la violencia mítica, cuando ésta se manifiesta como poder legislador. La violencia inmediata desvincula, carece de límites, en la medida que se deshace de todas las conexiones que se han establecido, históricamente, entre la violencia y los fines posibles. De ahí que Benjamin caracterice a la violencia divina como fulminante: porque desgarra lo que ha sido tradicionalmente relacionado o, en la esfera del derecho, delimitado. Es divina, justamente, por distintiva y ajena a toda referencia externa. De manera que, a diferencia de la violencia mítica, sangrienta para la mera vida en virtud de una impura e interesada conexión con ella, la divina aniquila la vida en un modo puramente quirúrgico, por amor de la vida, o sea, de lo espiritual de la vida (Benjamin, 1993: 60).

El poder de Dios es presentado, de esta forma, como mortal de necesidad para una vida puramente natural, y con ella para el derecho, pues con la mera vida se acaba su imperio (ibid). La mera vida es el mundo de la culpa, y su implacable aniquilación es justa redención, al llevarse a cabo en nombre de lo vivo, ya que lo vivo no equivale a una vida en sentido puramente natural, biológico. Lo vivo es algo más que la mera existencia, pues ésta no es algo privativo del ser humano, sino común a plantas y animales. Lo vivo es para Benjamin lo que en la existencia humana separa a ésta de su ser corporal, de su mero existir. Es lo que remite al orden divino mismo - a la creación-, desbordando la vida, sus bienes y sus normas. En pocas palabras, es la vida plena.

Con todo, las distinciones que Benjamin establece con el mundo del derecho, el mito y el destino no están aún completas. La violencia divina debe ser también distinguida de lo que los seres humanos construimos como manifestaciones suyas. Si 
bien la violencia revolucionaria es la más elevada manifestación humana de la violencia pura, para la humanidad resulta imposible decidir cuándo, en un caso concreto, la violencia es realmente pura. Y esto es así porque sólo la violencia mítica, no la divina, es susceptible de reconocerse con certeza, dado que el poder redentor de la violencia no es evidente para el ser humano (Benjamin, 1993: 64). Así pues, la violencia pura se separa a sí misma de sus propias manifestaciones reconocibles y determinables como tales. No obstante, esto no significa que esté afectada por la misma ambigüedad que es propia de la mítica. Que la violencia pura se separe de sus manifestaciones se debe a que es una violencia decisoria, determinante e incisiva. De ahí que su manifestación sólo pueda hacerse evidente por su "efectos incomparables" (ibid.). Esta unicidad de los efectos se debe a que no están en conexión con nada, a que son efectos puros, no más, pues, que eventos (en y para sí) decisivos del decidir.

Por consiguiente, la violencia pura es el poder de la separación, de la diferencia, al punto de que se separa de sí misma (de sus manifestaciones). Este poder de diferenciar y distinguir es presentado, finalmente, como una "violencia divina que es enseña y sello, nunca medio de ejecución sacra, por lo que puede denominarse eficaz"* (Benjamin, 1993: 64). La violencia divina impera como acción característica y distintiva. Con su acción se distingue a sí misma; ella es un fulminante, demostrativo y decisivo autorrealzamiento. Y la pureza de esta violencia no puede consistir sino en este permanente separarse de todo lo demás. Pues bien, justo a esta diferenciación sin fin es a lo que llama Benjamin justicia divina.

El empeño de Benjamin con la crítica, en definitiva, le condujo no sólo a convertir el objeto de la misma (la violencia) en la auténtica esencia de su mismo criticismo, sino que, en la búsqueda de un criterio para la violencia como principio, dio a la diferencia y la decisión críticas rango ontológico y metafísico. En el nombre de esta violencia divina rechazó cualquier otra forma de violencia. La violencia pura tiene su esencia en la decisión misma.
Esto es lo que la distingue como principio, el tener su criterio exclusivamente en ella misma.

En este sentido, la violencia divina benjaminiana guarda un notable paralelismo con la violencia soreliana, tendente a la destrucción de la autoridad, que es correspondiente con el que existe entre la violencia mítica y jurídica de Benjamin y la force de Sorel, dirigida a instituir y conservar la autoridad. Violencia divina, en un caso, y violence, en el otro, representan una especie de praxis pura, de acción sin una finalidad, que va más allá de cualquier intencionalidad e instrumentalismo, como ha señalado Jan-Werner Müller (2003). Esta praxis pura tiene que superar esa especie de rutina de apariencia natural que configura el ciclo opresivo e inmovilizante de la historia, y es en este preciso sentido que ella representa violence, Gewalt; es decir, una interrupción radical. Y éste, precisamente, es su valor ético, y político (Figal, 1979). No obstante, los discursos de Benjamin y Sorel se separan cuando el primero sitúa dicha praxis en el marco de una perspectiva de redención mesiánica, mientras el segundo la localiza en el de un activismo expresivo que hoy adquiere claras resonancias de performance antisistema.

\section{DE LA CRÍTICA A LA DECONSTRUCCIÓN}

Uno de los puntos de referencia clave del análisis de Derrida sobre la conexión entre derecho y violencia es, justamente, la crítica de la violencia de Benjamin (cf. Gasché, 1994 y Menke, 1994). Lo es en un sentido negativo, pues Derrida rechaza la excesiva confianza que Benjamín deposita en la empresa crítica, así como lo que él entiende como inquietante ambigüedad ético-política de su resultado. Pero también representa una referencia positiva, pues coincide con Benjamin en la necesidad de explorar la posibilidad de una justicia que vaya más allá de la puramente jurídica, si bien, como veremos, la exploración se realiza por una vía diferente y no conduce, en consecuencia, a un resultado idéntico.

\footnotetext{
*Traduzco aquí waltende por "eficaz", en contra de lo que es habitual; es decir, no como "soberana". El verbo alemán walten tiene dos acepciones fundamentales: la de herrschen (dominar, imperar) o la de wirken (obrar, producir o surtir efecto). Interpreto, como espero que quede claro en mi texto, que este segundo significado se ajusta mejor al sentido del concepto benjaminiano de göttliche Gewalt.
} 
Derrida ve en la crítica de la violencia de Benjamin un objeto perfecto para el ejercicio de la deconstrucción, al entender que las distinciones que lo articulan no sólo son extremadamente problemáticas, sino la expresión inequívoca de un "hipercriticismo" (Derrida, 2005: 77) que lo convierte en un texto "autodeconstructivo" (93). Si la deconstrucción del texto benjaminiano no ha de proceder de fuera, entonces la deconstrucción tiene que ser, en cierto modo, la misma experiencia que el texto "hace, primeramente, él mismo, de él mismo, sobre sí mismo" (Derrida, 2005: 78). Se trata, pues, de una "auto-hetero-deconstrucción" (ibid.), que frustra no sólo su vocación crítica, sino la misma firma que, en una especie de juego de palabras con el nombre del autor (Walter), y en nombre de la violencia divina, cierra el texto: die waltende Gewalt.

Según Derrida, lo que amenaza la distinción entre la violencia fundadora de derecho y la que lo conserva es, en el fondo, "la paradoja de la iterabilidad", que "hace que el origen deba originalmente repetirse y alterarse para valer como origen, es decir, para conservarse" (Derrida, 2005: 104). Y si la posibilidad de la violencia conservadora está inscrita por la iteración en el corazón de la fundadora, la distinción entre ambas se autodestruiría en su mismo intento de establecerse. Derrida cree que Benjamin era consciente de ello, pues de otra forma no alcanza a explicarse por qué, finalmente, la distinción entre estas dos violencias queda subsumida bajo otra, instalada en un nivel supuestamente más elevado, entre violencia mítica y divina. Pero la violencia divina resulta también indistinguible, porque su concepto exige una distinción pura, y como tal diferente de todas sus manifestaciones. La "ley apriorística de la iterabilidad" corrompería también, por principio, la pureza de la violencia divina, porque una violencia no instrumental se ve en el trance de tener que ceder ante lo que violentamente excluye, la mediación, el derecho, la mera vida.

De esta forma, nos encontraríamos, por un lado, con el Estado y su derecho, que representan la certidumbre decisoria en un dominio que es estructuralmente el de lo indecidible (el del destino y el mito), y, por el otro, con una justicia que, poniéndose más allá del Estado y su derecho, se inscribe en el dominio de la decisión sin conocimiento susceptible de fundamentar la toma de decisiones. Por consiguiente, "de una forma u otra, lo indecidi- ble está presente en ambos lados, y es la condición violenta o del conocimiento o de la acción. Pero conocimiento y decisión están siempre disociados" (Derrida, 2005: 131).

La superación de este problema irresoluble en el que, según Derrida, desemboca el "hipercriticismo" de Benjamin sólo es posible si se abandona el discurso crítico para pasar al deconstructivo. Y esa es la empresa a la que precisamente dedica Derrida la primera parte de su Force de loi, cuyo título es perfectamente ilustrativo de la intención de Derrida: $D u$ droit à la justice.

Deconstruir el derecho significa, de entrada, reducir éste a sus paradojas, poniendo de relieve que carece de un sentido determinable. Contra las apariencias, en él todo es transformación constante y aplazamiento significativo, différance, que está indisolublemente unida a la paradoja de su fundación, pues ésta no tiene otro soporte que la violencia, entendida en el sentido de fuerza arbitraria: "la operación que funda, justifica el derecho es una violencia performativa, y por tanto interpretativa, que en sí misma no es justa ni injusta, ya que ninguna justicia ni fundación preexistente podría garantizarla ni contradecirla o invalidarla" (Derrida, 2005: 33).

Esta conexión fundacional entre derecho y violencia debe ser entendida, pues, en su más profundo sentido; es decir, "no en el sentido de que el derecho estaría al servicio de la fuerza, como instrumento dócil, servil, y por tanto exterior, del poder dominante, sino que mantendría [...] una relación más interna y compleja. Su momento fundacional o instituyente mismo, por lo demás, no es nunca un momento inscrito en un tejido histórico homogéneo, puesto que precisamente lo desgarra con una decisión" (Derrida, 2005: 32). Además, esa fuerza es siempre también interpretativa y, como tal, lleva consigo una apelación a la creencia, por lo que el discurso se topa allí, en su mismo poder performativo, con su límite. Hay, pues, "un silencio amurallado en la estructura violenta del acto fundador", dice Derrida (2005: 33), porque no es exterior al lenguaje, y en ello precisamente radica lo que define como "el fundamento místico de la autoridad" (ibid.), generalizando en sentido wittgensteiniano la expresión de Montaigne.

Esta fundación irracional del derecho representa el punto de partida de una reivindicación de la justicia. El derecho es deconstrutible porque es construcción continua (mediante capas de sentido 
históricamente producidas, y como tales interpretables y transformables) $\mathrm{y}$, al carecer de fundamento racional último, tiene que autorizarse a sí mismo (Derrida, 2005: 36). La justicia, en cambio, es en sí misma - no como justicia jurídica, pues - inmune a la deconstrucción, porque la hay incluso allí donde no existe o no ha existido nunca. La justicia en sí, por consiguiente, queda convertida de esta forma en la misma posibilidad de la deconstrucción del derecho (Derrida, 2005: 36); o lo que es lo mismo, "la deconstrucción es la justicia” (Derrida, 2005: 35).

En el siguiente paso del proceso deconstructivo del derecho, Derrida se adentra por espacios donde resuena, de nuevo, el eco de Benjamin, pues la justicia es presentada como infinitud, incalculabilidad, rebeldía ante la regla, extrañeza ante la simetría, heterogeneidad y heterotropía (en el sentido foucaultiano); por lo tanto, como lo opuesto al derecho y su justicia, que representan estabilidad, calculabilidad, codificación, sistema (Derrida, 2005: 48). Ahora bien, si la justicia no es en sí misma jurídica, tampoco es extrajurídica (social, moral o política), y su distinción del derecho no es, en el fondo, una auténtica distinción (una oposición cuyo funcionamiento esté lógicamente reglado y sea técnicamente manejable), "porque el derecho pretende ejercerse en nombre de la justicia y ésta exige instalarse en un derecho que debe ser aplicable (constituido y aplicado, por la fuerza, 'enforced')" (Derrida, 2005: 49 s.). La justicia trasciende cualquier acción jurídica, y sin embargo la promueve como una demanda incondicional de la alteridad. No está desconectada de la realidad jurídica, como pura trascendencia, pero mantiene con ella una relación autocontradictoria, de insuperable separación y constante estímulo, de demanda insatisfecha de una justicia trascendente. En consecuencia, la deconstrucción se instala entre el derecho y la justicia, moviéndose permanentemente entre ambas (Derrida, 2005: 50), perfilando un modo de observación de derecho y mundo como unidad de la diferencia entre lo que es derecho y no lo es (Teubner, 2001: 42), por lo que, inevitablemente, se adentra en un terreno plagado de aporías (cf. Derrida: 50 ss.). No debería resultar extraño, en consecuencia, que la diferenciación entre la violencia jurídica y la justa no sólo sea impracticable antes de la toma de decisiones para la acción, como en Benjamin, sino también después de ellas, y que la cuestión relativa a los criterios de la misma sea remitida a un futuro indeterminado.

Este problema, por lo demás, está estrechamente relacionado con el carácter asociológico del método deconstructivo, originado por su desarrollo a partir de una distinción entre conciencia y habla que no admite un tercer valor, lo que impide a Derrida tomar en consideración la autonomía de la sociedad y diferenciarla de la conciencia individual. La deconstrucción del derecho queda limitada, así, al ámbito textual (e intertextual), ignorando, de hecho, todo lo relacionado con la reproducción del derecho como fenómeno social y, por tanto, con su capacidad de afrontar operativamente el problema de su fundación paradójica, en virtud de la cual las condiciones de posibilidad de su deconstrucción van cambiando históricamente.

\section{DE LA PARADOJA ESTRUCTURAL DEL DERECHO Y DE CÓMO ÉSTE SE DESHACE DE ELLA}

Cómo por medio de sus operaciones, estructuras y configuraciones institucionales pueda procesar de forma productiva su condición de sistema paradójicamente fundamentado el derecho es, precisamente, una de las más interesantes aportaciones de Luhmann a la sociología del derecho (cf. Luhmann, 1988). Y de ellas forma parte la reflexión del sociólogo alemán acerca de la relación entre derecho y justicia.

Luhmann se aproxima a esta relación partiendo de una distinción que, a diferencia de Benjamín y Derrida, localiza a la justicia dentro del propio sistema jurídico: es la distinción entre autorreferencia operativa y autorreferencia observacional o descriptiva. Esto significa, en primer lugar, que la justicia no es un valor ni un principio extrajurídico, de orden moral o político, que el derecho positivo deba realizar, o conforme al cual éste pueda ser objeto de crítica o deconstrucción. Y, en segundo lugar, que la justicia debe ser claramente distinguida de la validez del derecho, por cuanto ésta es un símbolo para la reproducción operativa - o sea, un recurso para facilitar la conexión recursiva de las operaciones jurídicas-, mientras que aquélla opera en el plano de la autoobservación y autodescripción del sistema como tal. En él, la idea de justicia — como la 
de escasez en la economía y las de bien común o legitimidad en la política- hace las veces de "fórmula de contingencia" (Luhmann, 1993: 217), que es tanto como decir que se trata de un recurso para la autoobservación, gracias al cual el derecho puede representarse como unidad sin caer en los problemas lógicos que se derivarían de observarse a sí mismo a través del código funcional (legal/ilegal, conforme a derecho/contrario a derecho) que todas sus operaciones manejan para poderse determinar como tales, esto es, como jurídicas.

Si el derecho intentase observar su unidad como sistema poniendo el foco en su código funcional se vería enfrentado a la paradoja de su fundamento: "lo legal sólo puede ser creado mediante la creación de lo ilegal", lo que significa "no que legal igual a ilegal, sino legal porque ilegal" (Luhmann, 2000: 22); $\mathrm{o}$, alternativamente, a una tautología: derecho es lo que hace el derecho; legal es lo que legalmente se determina como legal. Por eso, el derecho ha de instalar su autorreferencia sistémica en el plano de los programas que proporcionan los criterios de uso de dicho código, y justo entonces sobre la justicia, que funciona como una especie de "programa de programas" (Luhmann, 1993: 217) y sirve como punto de referencia de la consistencia del sistema jurídico.

La idea de justicia asume esta función y se estabiliza en su desempeño conforme el derecho se va diferenciando como sistema funcional (autónomo) de la sociedad, lo que significa, en términos de autoobservación y autodescripción, que ha de asumir su carácter contingente y su postulación como derecho positivo. En este marco, la habitual formulación de la justicia como principio o valor no es aleatoria ni gratuita, pues sólo así puede contribuir a disolver la paradoja estructural del sistema jurídico o desplegar la tautología que se presenta como alternativa.

La justicia, por tanto, no tiene nada que ver con una pura demanda de trascendencia del derecho, sino sólo con su más pura inmanencia; es decir, con la positividad de sus operaciones sistémicas, la programación o reglamentación de las mismas, o, todo lo más, con las relaciones entre el derecho y su medio social, y ello a efectos de facilitarle su desparadojización o destautologización. Es más, la reproducción sistémica del derecho - la toma de decisiones jurídicas - exige obviar cualquier aspiración trascendente.
Ahora bien, esta disposición no es privativa del sistema jurídico, sino común a cualquier otro sistema funcional de la sociedad moderna, con una excepción: la religión, pues sólo ella está capacitada para enfrentarse abiertamente a este problema y, en virtud de ello, para abordar de forma significativa el de la unidad de la diferencia, del que resulta la paradoja en su estado puro: la identidad de lo diferente (Luhmann, 1996).

Con este planteamiento, Luhmann se separa radicalmente del deconstructivismo de Derrida y del criticismo de Benjamin, en los que, como hemos visto, la justicia se postula como valor de contraste al orden jurídico positivo, fundamentado y conservado por el poder. Ahora bien, no a pesar de esta distancia, sino más bien en virtud de ella, el análisis que realiza Luhmann del significado de la violencia para el derecho mantiene interesantes puntos de contacto con el análisis de Derrida y, sobre todo, de Benjamin, en virtud de los cuales piezas importantes de los textos de ambos pueden ser incluidas en el análisis de la estructura y del proceso evolutivo del derecho.

El más relevante de estos puntos de contacto es, precisamente, el relativo al significado de la violencia para el derecho (cf. Luhmann, 1972: 106 ss.). Luhmann entiende que si la violencia es relevante para el derecho lo es más por su elevado potencial de rendimiento simbólico que por sus efectos materiales, por lo que su significación jurídica depende muy estrechamente de su generalización como símbolo. La representación demostrativa de la fuerza física, la ejecución simbólica, es vista, en consecuencia, como una exhibición a ello orientada, por lo que es preciso determinarla analíticamente como tal y no por las consecuencias materiales de su empleo efectivo.

Este punto de partida del análisis luhmanniano de la conexión entre derecho y violencia exige una nítida delimitación de violencia y coacción inmediata, pues el sentido de la primera no se agota en la segunda. Es más, en tanto que la acción a la que se refiere y espera deba tener algún grado de autonomía, la coacción es un medio de producirla excesivamente costoso. Por tanto, la violencia debe entenderse, ante todo, como un medio de representación y confirmación de normas, no de imposición de las mismas. Sólo así se puede explicar el uso primariamente represivo y vengador que de ella se hace en 
las relaciones jurídicas arcaicas; por ejemplo, en la muy extendida costumbre de la vendetta, con la cual no se trata tanto de sancionar al culpable, de dirimir un conflicto mediante una confrontación pública ni de obtener una reparación como, ante todo, de representar el aferramiento a la norma violada.

El recurso a la violencia, con todos los riesgos que conlleva, permite al damnificado por la violación de la norma afirmarse en su derecho, así como dejar claro su vínculo ante su grupo de parentesco y la validez de la norma ante la sociedad. Quien no está dispuesto a defender su derecho con la violencia lo pierde, pues justo es esta disposición lo que mantiene la integridad del derecho, lo que lo demuestra (cf. Mair, 1962). En las sociedades arcaicas, por consiguiente, la violencia responde al arquetipo de la violencia mítica en Benjamin: no es medio sino manifestación; algo que simboliza y produce, con su inclinación hacia la decisión, la congruencia de los distintos mecanismos fundadores de derecho. La violencia no sólo puede ser considerada un medio auxiliar de ejecución de un derecho válido en sí, sino que, como nos enseñan los viejos símbolos jurídicos, forma parte de la representación del derecho en la vida social, poniendo de manifiesto la selectividad que es propia de todo orden jurídico.

Sin embargo, con la evolución del derecho hacia su diferenciación funcional, la simbolización de la congruencia se separa progresivamente de su producción, lo que presupone el desarrollo de todo un complejo dispositivo institucional. El derecho, desde luego, no puede evolucionar hacia su forma moderna de articulación, funcionalmente diferenciada, si la violencia no está de su lado. Ahora bien, la violencia no puede representar ya un recurso sistemático de las propias proyecciones normativas, y como tal ha de ser disociada del derecho, adoptando la forma de acción aislada y no jurídicamente intencionada.

La evolución del derecho está vinculada, en consecuencia, a la domesticación de la violencia. La estrecha asociación existente entre uno y otra genera problemas que, en una sociedad cada vez más compleja por diferenciada, necesitan vías alternativas de solución. Los perversos efectos políticos y económicos de la misma han sido, por eso, el origen de diversos y bien conocidos intentos de regular su empleo. A este respecto, Luhmann hace hincapié en un problema que, sin embargo, no ha sido tan frecuentemente analizado y debatido, pero que para él tiene mucha significación, como es el que, en cuanto fundamento del poder, la violencia muestra una excesiva independencia estructural, al presuponer sobre todo una fuerza irresistible y pasar por encima de órdenes de estatus, interconexiones entre roles, pertenencias grupales y valores. Justo por eso entiende Luhmann que la violencia es casi universalmente utilizable; es decir, por ser en buena medida indiferente a momentos, lugares y situaciones en los que se desenvuelve la acción, y por eso también al nivel de complejidad alcanzado por el orden jurídico y la sociedad de la que es parte.

En esta elevada independencia de la violencia ve Luhmann, pues, no sólo un recurso evolutivo (debido a su poder innovador y a la facilidad de organizarla centralizadamente), sino también una amenaza permanente para el avance estructural sin graves sobresaltos de la sociedad. La violencia puede ser tanto un soporte del orden establecido como una amenaza para el mismo. En sí misma no contiene garantía alguna de ser el fundamento de proyecciones normativas institucionalmente amoldables, pues también puede ser un medio de expresión e imposición de aspiraciones normativas defraudadas por el orden establecido. Como violencia es ambivalente, indiferente a ambos usos, y precisamente en ello se apoyó Sorel para proponer su distinción entre force $\mathrm{y}$ violence.

La forma más natural, y por eso históricamente recurrente, de reaccionar a la infracción de una norma es una conducta punitiva, y con frecuencia mortífera, por parte de quien sufre las consecuencias o de su círculo de allegados. Esta autoadministración de justicia no puede ser sólo contemplada como un mecanismo sustitutorio de los fallos o incapacidades del aparato judicial y las fuerzas de seguridad, sino que, según Luhmann, viene a poner de manifiesto la conexión estructural existente entre derecho y violencia. El derecho se evidencia cuando es violado, y en virtud de la duda que ello suscita parece natural la reacción excesiva de asentar lo jurídico sobre lo antijurídico.

Parece lógico, por tanto, que la historia del derecho presente una lucha constante por eliminar la espontaneidad arbitraria de la reacción, pues de lo contrario sería difícil poder distinguirla de la violación normativa. Pero como el derecho se representa a sí mismo concretamente en la violencia, la institucionalización de la reacción a su quebrantamiento 
tiene pocas posibilidades de contener la propensión a la venganza. De ahí que Luhmann entendiese que el punto de partida de una regulación efectiva reside menos en una limitación del alcance de la venganza que en determinar sus condiciones y formas, para así forzarla a convertirse en una violencia razonadora y razonada. En términos prácticos: la clave está en que los perjudicados, las víctimas, estén sometidas a una situación de inferioridad de poder lo suficientemente grande como para que se hagan transigentes.

Así pues, la reordenación de esta conexión originaria entre derecho y violencia en el proceso evolutivo de la sociedad dependerá, ante todo, de que se logre la monopolización de las decisiones sobre el empleo de la violencia por parte del Estado. Este monopolio, que presupone la diferenciación entre roles especializados en la toma de decisiones jurídicas y roles para su ejecución, es lo que dará a las normas que han de constar como jurídicas en los procesos decisorios organizados una seguridad suficiente de que se podrá renunciar cada vez más a la violencia como recurso expresivo del derecho. El lugar de la violencia expresiva — símbolo, manifestación- será poco a poco ocupado por las decisiones; mientras, la ejecución de las sanciones será puesta a resguardo, en un espacio oculto a la vista de la sociedad. De este modo, el ejercicio explícito y abierto de la violencia se irá haciendo progresivamente menos necesario, y cuando se produzca será contemplado como un síntoma de fracaso político, por lo que, incluso, puede ser objeto de provocación contestaría, a efectos de presentar al orden establecido como un orden ilegítimo.

Con todo, aunque la violencia ceda en su función simbólica, demostrativa, Luhmann insiste en que no por ello se convierte en prescindible. Y ello nos conduce a otro factor decisivo para la reordenación de la relación entre derecho y violencia en las sociedades complejas: el que la demostración del primero ha de hacerse más abstracta, específica y diferenciada. El derecho se convierte en un aparato de normas susceptibles de ser abstractamente formuladas, que han de guardar una cierta consistencia y ser interpretables en cada caso concreto. Se abre entonces la posibilidad de diferenciar entre las cuestiones de hecho y las de derecho, así como entre sus correspondientes fuentes de información, lo que da a los procedimientos de producción jurídica una mayor autonomía, pues no son meros procesos normativos (de creación de normas) ni tampoco una sucesión de actos determinados sin más por los hechos (cf. Luhmann, 1983). La demostración del derecho radicará, ahora, en la superación de esta diferencia, en la respuesta conjunta a cuestiones fácticas y normativas, que se presenta como decisión.

La domesticación de la violencia presupone, como vemos, fundamentos evolutivos muy complejos y dificultosos de establecer, cuyo resultado es la separación entre causación y simbolización de la congruencia jurídica. Para conseguir un grado mínimo de congruencia, el disponer de la violencia como respaldo de las normas jurídicas sigue siendo indispensable, aunque no tanto a efectos de motivar a los desviacionistas (efectivos y potenciales) como a los de generar una confianza generalizada en ellas. Del mismo modo que el valor del dinero como medio de la comunicación económica descansa sobre la expectativa de que en general se espera que sea aceptado como un valor - y no sólo sobre la expectativa de su inmediata aceptación en una concreta transacción, que como tal, sin la simultánea expectativa de las expectativas de cualquier potencial receptor, no sería convincente-, la congruencia de los mecanismos jurídicos descansa sobre la expectativa de que en general es esperado que el derecho cuente con la cobertura de la violencia centralizada por la institución estatal. Gracias a ello, el derecho puede economizar un recurso tan escaso en las sociedades complejas y diferenciadas como es el consenso, así como hacerse compatible con un alto grado de diversificación en lo moral y en las motivaciones íntimas de los individuos.

Por consiguiente, para el eficaz funcionamiento de un orden jurídico efectivo en la compleja sociedad moderna es mucho más importante la seguridad de las expectativas reflexivas o de segundo orden (expectativas acerca de expectativas) que la relativa al cumplimiento de las expectativas de primer orden (expectativas acerca de conductas). La decepción de expectativas de primer orden puede afrontarse mediante soluciones que, aunque no sean las óptimas, pueden ser lo bastante satisfactorias, utilizando recursos auxiliares, haciendo uso de alternativas sustitutivas y de mecanismos compensatorios. Pero la certidumbre de las expectativas normativas de segundo orden descansa siempre, en último término, en la violencia. Ahora bien, en la sociedad moderna, por contraste con las sociedades arcaicas y las tra- 
dicionales, esta función productiva $-\mathrm{y}$, en consecuencia, tanto fundadora como conservadora- de la violencia puede alcanzar un grado mucho más alto de especialización, y, apoyándose en ello, conseguir una muy alta diferenciación de la función de simbolización del derecho. El respaldo de la violencia ya no se presenta en forma de una exitosa autoafirmación de las expectativas, pues al referirse a contenidos desconocidos y cada vez más variables ya no puede depender del recurso directo a la fuerza y de las circunstancias concretas.

\section{A MODO DE CONCLUSIÓN}

La imposibilidad de decidir los problemas jurídicos (Benjamín), el fundamento místico de la autoridad (Derrida) o la incompletitud lógica del derecho (Luhmann) son tres fórmulas diferentes pero equivalentes de enunciar el problema de fondo de la relación entre derecho y violencia. Pero esta importante coincidencia no da origen ni a un tratamiento común ni, menos aún, a unos resultados coincidentes.

Como hemos visto, Benjamin parte de la distinción entre violencia sancionada y no sancionada, a la que se superpone después la más importante entre violencia fundadora de derecho y conservadora de derecho, con el resultado de que, dentro de la violencia jurídicamente sancionada, el mantenimiento de esta segunda diferencia es condición necesaria pero no posible de la validez del derecho. En toda operación que conserva el derecho, que lo reproduce, hay un momento fundacional (productor), sólo por el hecho de que es preciso decidir. Por lo tanto, el derecho destruiría la diferencia sobre la que basa su validez, y ello de forma constante (no sólo en los casos excepcionales, "decisivos", de los que habla Carl Schmitt), al intentar no caer en los abismos de sus indeterminaciones y tener que servirse para ello de la violencia. De este modo, la desalentadora experiencia de la imposibilidad de decidir todos los problemas jurídicos viene a ser hecha coincidir con la ubicuidad jurídica de la violencia.

Pero, como pone de relieve Luhmann, vista desde el derecho como sistema social, esta opacidad no bloquea el proceso de toma de decisiones jurídicas. Sabiéndose cubierto por la violencia (en tanto que legítimamente monopolizada por el Estado), el derecho puede soportar su ambigüedad constitutiva $y$, pese a ella, sentirse capaz de decidir cualquier caso. Luhmann, entonces, se pregunta por qué llamar a esto violencia y qué podría significar, más allá de un concepto que viniera a expresar "el resentimiento de un escritor" (Luhmann, 2000: 17), así como si el hacer su dominio congruente con el de un derecho necesariamente indeterminado no representa un simple retorno a Kant. Como alternativa, y para evitar tener que adentrarse por la vía, sociológicamente intransitable, de la apelación a la trascendencia de un violencia/justicia divina, Luhmann propone la fórmula de la ambigüedad del derecho, mediante la cual no sólo asume sino que pretende generalizar el tratamiento tradicional (en la filosofía y la teoría jurídicas) del problema de la incompletitud lógica del derecho y de su ambivalencia. Esto, lógicamente, le lleva a tener que preguntarse cómo puede apañárselas el derecho con la amalgama de indeterminación y determinación que impregna todas sus operaciones, estructuras e instituciones. Al respecto, el sociólogo alemán señala que la semántica de la violencia no proporciona ninguna indicación útil, y sólo sirve para distorsionar el problema de fondo: la paradoja estructural a la que el derecho, como todo sistema autorreferencial, debe enfrentarse permanentemente; es decir, en este caso, que lo jurídico sólo puede ser producido a la vez que lo antijurídico, y por eso es indecidible si el derecho vale por derecho o contra derecho.

Lo que Luhmann viene a proponer con su forma de tratar la cuestión de la conexión entre derecho y violencia es, en definitiva, una "sociologización" de su paradoja constitutiva, que se contrapone nítidamente con el intento - vehiculado por el concepto de justicia- de darle una solución trascendente, bien por la vía de un criticismo de nuevo cuño (Benjamin y su justicia/violencia divina), bien por la de la deconstrucción (Derrida y su justicia asentada sobre una filosofía de la alteridad). Y "sociologizar" la paradoja constitucional del derecho significa escrutar cómo el derecho (operativa, estructural e institucionalmente) se desparadojiza, es decir, crea un orden funcional capaz de sortear el riesgo del caos, siempre latente, debido a su constitución paradójica. En cambio, tanto Benjamin como Derrida, apelando a una noción de justicia que no es, como en Luhmann, una fórmula de consistencia o contingencia jurídica, sino apelación, abismo, ruptura, experiencia de la contradicción, buscan justo lo opuesto: in- 
troducir el caos en el derecho. Es la diferencia que resulta de afrontar el problema de fondo común a todos ellos "como una decisión sub specie aeternitatis o como una decisión sub specie societatis" (Teubner, 2003/04: p. 12).

La imposibilidad de autolegitimar (jurídicamente) los valores y criterios fundamentales del derecho, resultante de esta paradoja estructural, fuerza al derecho a buscar una decisión que corte de raíz cualquier posibilidad de bloqueo decisorio. Y esto, según Luhmann, significa que dicha decisión no puede establecerse en un habermasiano ámbito deliberativo, porque en el marco de los fundamentos paradójicos del derecho la distinción y ponderación analíticas no pueden tener fin. Si los fundamentos de la decisión son paradójicos, ésta tiene que salir, dando un salto, de la paralizante controversia entre aspiraciones evidentes e indivisibles.

El tono decisionista de la perspectiva analítica luhmanniana se hace entonces perfectamente evidente. Pero el decisionismo carece de interés para Luhmann, pues, indiferente a toda cuestión que tenga que ver con el problema del "origen", a lo que él presta atención preferente es a cómo el derecho, en cuanto sistema social, es capaz de lograr lo que para cualquier observador es evidente: que se toman constante y eficazmente decisiones jurídicas.

Para ello es condición indispensable que los presupuestos del sistema puedan presuponerse a sí mismos; es decir, en el caso del derecho, que cuando se pregunta por los fundamentos de una determinada decisión jurídica sea posible remitirse a decisiones precedentes, a reglas y jerarquías normativas, así como a cadenas deductivas que conducen del caso concreto a determinaciones normativas últimas. Ahora bien, si se pregunta por los fundamentos de estas determinaciones últimas, que valen como presupuestos de la producción de sentido y de operaciones del sistema, no se obtiene una respuesta clara, pues cualquiera que se dé presupone ya la base del derecho.

El derecho, pues, es incompleto - su movimiento es autonegador-, y por eso es a la vez determinado e indeterminado. No hay derecho indisputable alguno a operar con la distinción entre lo legal y lo no legal; lo uno es producido siempre con lo otro, y la conversión de la paradoja resultante en una mera contradicción entre los dos valores de un código funcional (legal e ilegal) que se excluyen mutuamente (legal ${ }^{1}$ ilegal), así como el autoposicionamiento del orden jurídico en el primero de ellos para operar con dicha contradicción (toda decisión acerca de qué es legal o ilegal ha de ser legal), requiere de una decisión que no puede ser fundamentada en los términos del propio orden. Por consiguiente, como señaló Carl Schmitt (1990: 16), aunque el concepto de orden jurídico "se aplique de forma irreflexiva como algo evidente", dado que "contiene el antagonismo de los dos elementos dispares del derecho", al igual que cualquier otro orden "descansa sobre una decisión y no sobre una norma". La institución de este código puede entenderse, entonces, como paso de un estado ajurídico a otro jurídico, y bien justificar la transición misma en virtud de la gran ventaja que representa disponer de un orden jurídico, como Kant, o bien, a lo Benjamin, criticarla como violencia.

A pesar de la renuencia de Luhmann hacia el decisionismo jurídico, no resulta extraño, pues, que el eco de Schmitt sea perfectamente distinguible en muchos pasajes de su sociología jurídica. Por ejemplo, cuando Luhmann (1993: 281) señala que "el derecho presupone una paz afianzada si quiere ser algo más que un mero condicionante de la violencia", viene a coincidir con la afirmación de Schmitt de que "toda norma general requiere que las condiciones de vida a las que ha de aplicarse efectivamente y que han de quedar sometidas a su regulación, tengan configuración normal", porque "la norma exige un medio homogéneo", y "esta normalidad fáctica no es un mero "supuesto externo", sino "antes bien, forma parte de su validez inmanente", pues "no existe una sola norma que fuera aplicable a un caos" (Schmitt, 1990: 19 s.).

Esta resonancia es perfectamente audible también cuando, tras señalar que en la modernidad temprana aún estaba muy presente la conexión entre el problema de una jurisdicción eficaz o ineficaz y la búsqueda violenta del derecho, Luhmann señala que "hoy puede reconocerse todavía en la anomalía que representa el derecho de legítima defensa y en las leyes de emergencia. Siguen existiendo, pues, casos residuales, límite, en las que el derecho, bajo condiciones jurídicamente regladas, autoriza a actuar contra él mismo. Y no es por azar que en tales casos se legitime el uso de la violencia y se omita el recurso típicamente jurídico a un procedimiento judicial" (Luhmann, 1993: 285). La consecuencia 
que saca Luhmann de ello es que "siempre que la violencia entra en escena aparece con ella la paradoja de la codificación jurídica, pero lo hace de una forma que es de inmediato desarrollada dentro del propio derecho, condicionada mediante regulaciones, y de esta forma haciéndose invisible como paradoja" (ibid.). Podemos, entonces, con Schmitt (1990: 21), preguntarnos de dónde obtiene el derecho, como unidad sistemática, esa capacidad de regular a fondo los casos en los que se suspende a sí mismo, circunscribiéndolos con la mayor precisión posible. La respuesta de Schmitt (1990: 20) es bien conocida: el derecho es siempre "derecho de una situación determinada", y es el "soberano" quien crea y garantiza esa situación en su totalidad. En consecuencia, "él tiene el monopolio de esta decisión última", en la que el decidir como tal se separa de la norma jurídica y "la autoridad demuestra que para crear derecho no necesita tener derecho"; o dicho más radicalmente aún, con la fórmula del propio Luhmann: legal porque ilegal. Y esto significa, en último término, que, jurídicamente, ese presupuesto de todo orden de normas positivas que es la "soberanía" no consiste tanto en el monopolio de la coacción o del mando como en el de la decisión (ibid.).

\section{BIBLIOGRAFÍA}

Benjamin, W. (1993): Zur Kritik der Gewalt und andere Aufsätze. Frankfurt, Suhrkamp.

Derrida, J. (2005): Force de loi. Le "Fondament mystique de l'autorité". París, Galilée.

Figal, G. (1979): "Die Ethik Walter Benjamins als Philosophie der reinen Mittel”, en G. Figal y H. Folkers, Zur Theorie der Gewalt und Gewaltlosigkeit bei Walter Benjamin. Heidelberg, FEST; pp. 1-24.

FolKers, H. (1979): “Zum Begriff der Gewalt bei Kant und Benjamin”, en G. Figal y H. Folkers, op.cit.; pp. 25-57.

GAschÉ, R. (1994): “Über Kritik, Hyperkritik und Dekonstruktion: Der Fall Benjamin”, en A. Haverkamp (ed.), Gewalt und Gerechtigkeit. Derrida-Benjamin. Frankfurt, Suhrkamp; pp. 196-216.

Hegel. G.W.F. (1986): Grundlinien der Philosophie des Rechts (Werke, 7). Frankfurt, Suhrkamp.

Kant, I. (1956): Die Metaphysik der Sitten (Werke, 4). Wiesbaden, Insel.

LuHManN, N. (1972): Rechtssoziologie. Reinbek, Rowohlt.

Luhmann, N. (1983): Legitimation durch Verfahren. Frankfurt, Suhrkamp.

Luhmann, N. (1988): "The Third Question: The Creative Use of Paradoxes in Law and Legal History", Journal of Law and Society, 15 (2); pp. 153-165.

Luhmann, N. (1993): Das Recht der Gesellschaft. Frankfurt, Suhrkamp.

Luhmann, N. (1996): “Die Sinnform Religion”, Soziale Systeme, 2 (1); pp. 3-33.

Luhmann, N. (2000): "Die Rückgabe der zwölften Kamels: Zum Sinn einer soziologischen Analyse des Rechts", Zeitschrift für Rechtssoziologie, 21 (1); pp. 3-60.

MaIR, L. (1962): Primitive Government. Harmondsworth, Pelican Books.

MenKe, B. (1994): "Benjamin vor der Gesetz: Die Kritik der Gewalt in der Lekture Derridas", en A. Haverkamp, op. cit.; pp. 217-275.

Montaigne, M. De (2002): Ensayos. Madrid, Cátedra

MüLleR, J.W. (2003): "Myth, Law and Order: Schmitt and Benjamin Read Reflections on Violence", History of European Ideas, 29 (4); pp. 459-473.

Pascal, B. (1981): Pensamientos. Madrid, Alianza.

Platón (2004): Gorgias (Diálogos, 2). Madrid, Gredos.

Schмiт, C. (1990): Politische Theologie. Berlín, Duncker \& Humblot.

Sorel, G. (2005): Reflexiones sobre la violencia. Madrid, Alianza.

Teubner, G. (2001): "Econmics of Gift - Positivy of Justice: The Mutual Paranoia of Jacques Derrida and Niklas Luhmann", Theory, Culture \& Society, 18 (1); pp. 29-47.

Teubner, G. (2003/4): "Dealing with Paradoxes of Law: Derrida, Luhmann, Wiethölter", Storrs Lectures of Yale Law School. 